\title{
A Sequential Nonlinear Random Fractional Differential Equation: Existence, Uniqueness and New Data Dependence
}

\author{
Hafssa Yfrah $^{1}$, Zoubir Dahmani ${ }^{2}$, Mehmet Zeki Sarikaya ${ }^{3}$, and Farooq Ahmad ${ }^{4}$ \\ ${ }^{1}$ University of Mostaganem \\ ${ }^{2}$ UMAB UNIVERSITY \\ ${ }^{3}$ Duzce Universitesi \\ ${ }^{4}$ Bahauddin Zakariya University, Multan, 60800, Pakistan
}

May 24, 2020

\begin{abstract}
In this work, we are concerned with a sequential nonlinear random differential equation of fractional order with nonlocal conditions. This is the first time in the literature where sequential problems and random ones are combined and considered. An existence and uniqueness of solutions for the problem is obtained by means of an appropriate random fixed point theorem. Then, new concepts on the sequential continuous and fractional derivative dependence are introduced. At the end, some results of stability on random, as well for deterministic, data dependence are discussed.
\end{abstract}

\section{Hosted file}

YfrahDahmaniFarooq.pdf available at https://authorea.com/users/325703/articles/453708-asequential-nonlinear-random-fractional-differential-equation-existence-uniqueness-andnew-data-dependence

\section{Hosted file}

YfrahDahmaniFarooq.tex available at https://authorea.com/users/325703/articles/453708-asequential-nonlinear-random-fractional-differential-equation-existence-uniqueness-andnew-data-dependence 